\title{
A Re-evaluation of the Eucnemidae larval characters (Coleoptera)
}

\author{
Jyrki Muona ${ }^{1,2} \&$ Marianna Teräväinen ${ }^{1,3}$ \\ 1 Finnish Museum of Natural History, Zoological Museum. Helsinki, Finland. \\ 2 ORCID: http://orcid.org/0000-0003-2771-1171. E-mail: jyrki.muona@helsinki.fi (corresponding author) \\ 3 ORCID: https://orcid.org/0000-0002-4624-011X. E-mail: marianna.teravainen@helsinki.fi
}

\begin{abstract}
The larval characters of Eucnemidae are re-evaluated. Tribe Schizophilini Muona, 1993 is considered to merit subfamily rank as Schizophilinae Muona new status. Larval characters congruent with previously used adult morphological characters support the earlier published sister-group hypotheses for lignicolous eucnemids with one exception, Pseudomeninae, which is here split resulting in the following evolutionary hypothesis: (Pseudomeninae (Schizophilinae (Paleoxeninae (Melasinae, Eucneminae, Macraulcinae)))). The position of three remaining clades, Anischiinae, Perothopinae and Phyllocerinae remain ambiguous.
\end{abstract}

Key-Words. Evolution; Phylogenetics; Coleoptera; Eucnemidae.

\section{INTRODUCTION}

Muona (1993) presented an evolutionary hypothesis for the family Eucnemidae on the basis of 80 binary adult morphological characters; both external and internal features were included. Lawrence et al. (2007) added COI data and 60 binary larval morphological characters to their adult character set in an analysis of Eucnemidae relationships. Both these analyses recovered the same hypothesis for Eucnemidae, the latter study clarifying the position of Perothops Laporte and including Anischia Fleutiaux in Eucnemidae.

Lawrence et al. (2011) used 366 taxa and more than 600 binary adult and larval morphological characters in their "all beetle" analysis, recovering the previously found clade (Anischiinae (Melasinae + Macraulacinae)). Kundrata et al. (2014) analyzed the Elateroidea relationships with sequence data. Depending on the alignment used, they had 4848 to 5302 homologous positions as characters, recovering the previously suggested eucnemid clade (Anischiinae (Melasinae + Macraulacinae + Eucneminae)).

All four studies found support for the same within family relationships of Eucnemidae. Lawrence et al. (2011) and Kundrata et al. (2014) appeared to differ strongly on the position of Elateridae, however. We suggest that this disagreement may be less dramatic than one might think by looking at the trees they presented. In Lawrence et al. (2011, cladogram 3) all nodes are poorly supported. Only Elateridae and Eucnemidae have a more than 50\% support, the support for their relationship to each other as well as to Brachypsectra LeConte, Aulonothroscus Horn and Cerophytum Latreille is below 50\%. In Kundrata et al. (2014) the bootstrap values indicate many well supported groups, but the relationships between the groups are again either poorly supported or not supported at all (Fig. 1). The lack of resampling support in the latter study is in fact an important result that should have been discussed in detail. Contrary to the view presented in the article, the support for multiple origins of the clicking apparatus in Elateroidea is not established. Actually, the result suggests another, in our view much more interesting scenario. Neither this molecular data nor previous morphological data lend support for a monophyletic Elateridae. The fact is that no study this far has recovered stable synapomorphies for this family.

Kundrata \& Bocak (2011) have shown that driliids appear to be derived elaterids. Kusy et al. (2018) give further evidence of "modified" elaterids. Indeed, the next step is to find further sister-groups for other monophyletic groups of "non-elaterids" within the "Elateridae". If so, the whole idea of click-beetles as a clade has to be abandoned - unless we are prepared to accept all Elateroidea s.l. as one family - rather than refusing to accept that Elateridae is not a natural group but just things we used to see as similar.

It is our view that the problem of unclear elateroid relationships may extend to Eucnemidae sensu Muona (1993) as well. It is possible that this 


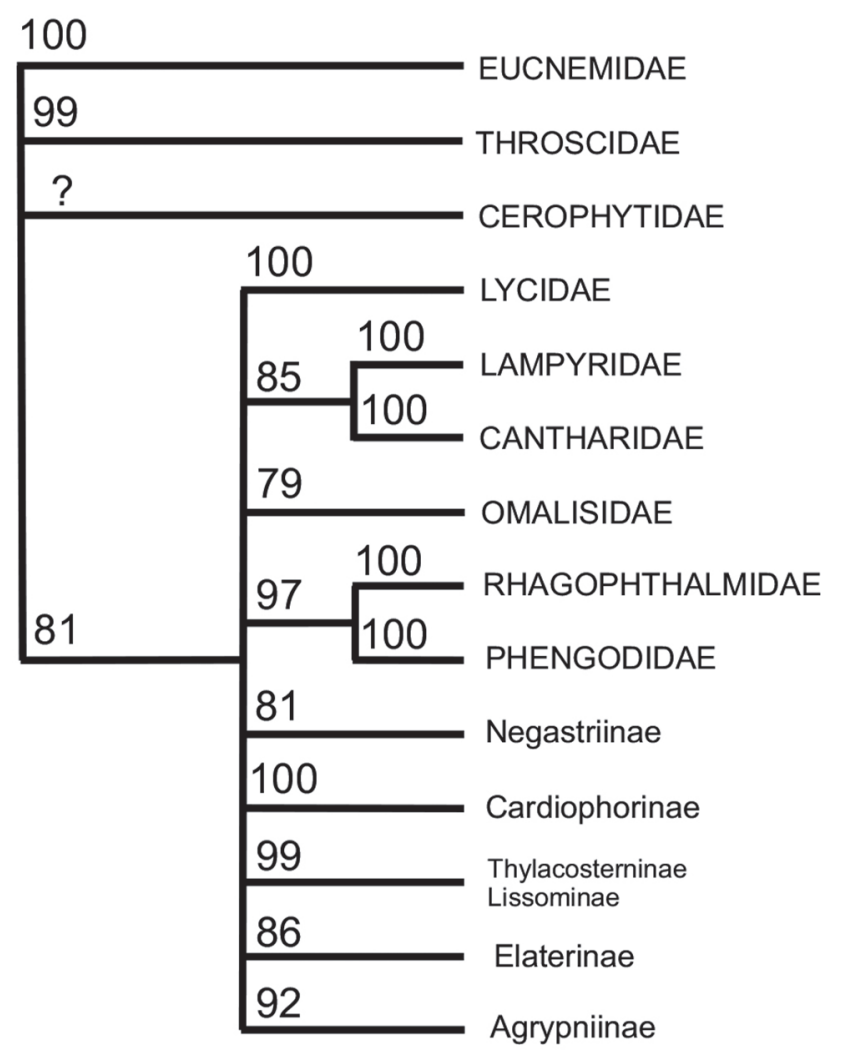

Figure 1. Kundrata et al. (2014) elateroid relationships hypothesis with unsupported bootstrap nodes removed.

family should be split and the relationships of the basal eucnemid lineages with Cerophytidae, Throscidae and Elateridae reconsidered. Neither Lawrence et al. (2011) nor Kundrata et al. (2014) included any of the basal eucnemid groups (sensu Muona, 1993; Perothopinae, Phyllocerinae, Pseudomeninae and Palaeoxeninae) in their analysis. Thus it is unknown whether these taxa would contribute something new to the result. The characters we point out certainly suggest this to be the case.

In the present paper we discuss the Eucnemidae larval types and the putative synapomorphies they possess. Böving \& Craighead (1931), van Emden (1932) and Crowson (1955) keyed out Eucnemidae using larval features, but the diversity of existing forms was not known to them. Much new information has come to light since. The champions of early eucnemid larval descriptions were J.C.M. Gardner in India, B. Burakowski in Poland, T-E. Leiler, S. Lundberg and T. Palm in Sweden and B. Mamaev in Russia, today we owe much to the diligent efforts of R. Otto in the US.

It is our great pleasure to offer this paper in celebration of Professor Cleide Costa on her $80^{\text {th }}$ birthday. Her contributions to larval coleopterology are many and of course include the Eucnemidae as well!

\section{MATERIAL AND METHODS}

We use as the backbone for our discussion the evolutionary hypotheses presented in Muona (1993) and Lawrence et al. (2007), as they are the only analytical studies including a full set of Eucnemidae higher categories. A list of descriptions available and material seen is presented separately (Table 1). Our approach focuses on the structures of the head and prothorax, but other features are included when relevant. Finally we compare the larval features to the result of the existing morphological hypothesis.

Eucnemidae taxa are listed in the same order as in Muona (1993) (Anischiinae added, Lawrence et al., 2007). This order is based on phyletic sequencing (Nelson, 1974). Thus every named taxon is the sister-group of all the remaining taxa of the same rank. Thus Perothopinae is the sister-group of all the other Eucnemids, and Melasinae is the sister-group of Eucneminae + Macraulacinae. Within subfamilies, tribes are listed in the same fashion. The Melasinae tribes Melasini and Hylocharini as well as the Macraulacinae tribe Nematodini are discussed separately.

The only detailed larval data set with good coverage of Eucnemidae taxa is in Lawrence et al. (2007). We will refer to some of the characters in that publication with the number used in it (ranging from c77 to c118).

MT took all the photographs except for 2E, 3D, 4A-C, 5A, 6A (JM) and 2F (after Lawrence et al., 2017).

\section{Eucnemidae: Perothopinae}

Head (Lawrence et al., 2007, figs. 26-31): Head capsule smooth (c84), undivided (c83), antennae located on surface as in all Elateridae, Cerophytidae, and Throscidae, in contrast to all other Eucnemidae (c85). Labrum fused to head as in all other discussed taxa except Phyllocerinae and Pseudomenini: Pseudomenini (c88). Number of antennomeres reduced as in all Eucnemidae except Phyllocerinae and Pseudomeninae and in contrast to Elateridae, Cerophytidae and Throscidae (c86). Mandibles with retinaculum as in Elateridae in contrast to other Eucnemidae and Cerophytidae and Throscidae (c97), free, elongate and inwardly curved biting as in Pseudomenini, Phyllocerinae, Anischiinae and most Elateridae, different from those of Throscidae and Cerophytidae as well as other Eucnemidae. Maxillolabial complex contiguous with epicranium on each side but incapable of movement, as in Cerophytidae, Throscidae, Pseudomeninae and Anischiinae, contrary to other Eucnemidae (completely fused) and Elateridae (freely movable). Presternum subtriangular, lightly pigmented, with paired oblique endocarinae, similar to that of Phyllocerinae, Pseudomeninae, Anischiinae and Palaeoxeninae. Legs five-segmented as in Phyllocerinae, Pseudomeninae and Elateridae, Cerophytidae and Throscidae, but in contrast to those of other Eucnemidae, which are tiny and either one segment (Anischiinae) or with seta in place of leg. Abdominal segments without microtrichial patches and areoles as in Elateridae, Cerophytidae, Throscidae, contrary to other Eucnemidae except Phyllocerinae. Segment IX with small, simple urogomphi. Spiracles with closing apparatus as in other Eucnemidae, all Cerophytidae and Throscidae, in contrast to Elateridae. 
Table 1. List of taxa. Species marked with an "**" were available for personal inspection.

\begin{tabular}{|c|c|}
\hline \multicolumn{2}{|l|}{ EUCNEMIDAE } \\
\hline Perothopinae & Perothops sp. [Lawrence et al., 2007] \\
\hline Phyllocerinae & Phyllocerus sp. [Gilyarov, 1979; Klausnitzer, 1997] \\
\hline Pseudomeninae & Pseudomenes bakewelli (Bonvouloir)*, Australia, ACT \\
\hline Schizophilinae & Schizophilus subrufus (Randall)* [0tto \& Young, 1998] \\
\hline Palaeoxeninae & Palaeoxenus dohrni (Horn)* [Böving \& Craighead, 1931; Chang et al., 2016] \\
\hline Anischiinae & Anischia kuscheli Lawrence* [Lawrence et al., 2007] \\
\hline \multicolumn{2}{|l|}{ Melasinae } \\
\hline Melasini & Isorhipis melasoides (Castelnau)* [Mamaev, 1976]; I. obliqua (Say)* [Van Horn, 1909]; Melasis buprestoides (Fabricius)* [Leiler, 1976]; Melasis pectinicornis Melsheimer* \\
\hline Hylocharini & $\begin{array}{l}\text { Hylochares cruentatus (Gyllenhal)* [Brüstle \& Muona, 2009]; H. harmandi Fleutiaux [Mamaev, 1976]; H. nigricornis (Say)* [Peterson, 1960]; H. populi Brüstle \& Muona* } \\
\text { [Brüstle \& Muona, 2009] }\end{array}$ \\
\hline Calyptocerini & Otho sphondyloides Germar* [Leiler, 1976] \\
\hline Xylobiini & Agalba sp. * , Australia, Queensland; Proxylobius gardneri (Fleutiaux) [Gardner, 1935]: Xylophilus corticalis (Paykull)* [Leiler, 1976]; X. ussurienis Mamaev [Mamaev, 1976] \\
\hline Epiphanini & $\begin{array}{l}\text { Hylis cariniceps (Mannerheim)* [Leiler, 1976]; H. foveicollis (Mannerheim) [Leiler, 1976]; H. procerulus (Mannerheim)* [Leiler, 1976]; H. olexai (Mannerheim) [Lucht, } \\
\text { 1981] }\end{array}$ \\
\hline Dirhagini & 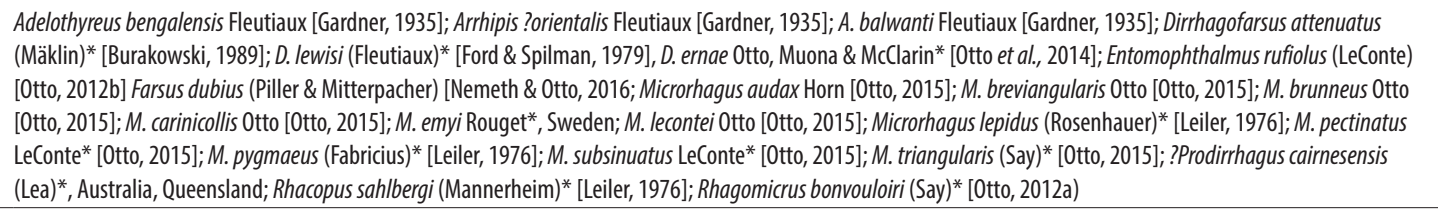 \\
\hline \multicolumn{2}{|l|}{ Eucneminae } \\
\hline Mesogenini & Stethon pectorosus LeConte [0tto \& Gruber, 2016] \\
\hline Eucnemini & Eucnemis capucinus Ahrens* [Palm, 1955; Lundberg, 1962; Leiler, 1976]; E. zaitzevi Mamaev* [Mamaev, 1976]; Poecilochrus bengalensis Fleutiaux [Gardner, 1935] \\
\hline Galbitini & Arisus bituberculatus Fleutiaux [Gardner, 1935]; Galbimorpha agastoceroides Fleutiaux [Gardner, 1935]; Galbites fulvus Fleutiaux [Gardner, 1935] \\
\hline \multicolumn{2}{|l|}{ Macraulacinae } \\
\hline Euryptychini & Euryptychus lewisi Fleutiaux [Mamaev, 1976]; ?Euryptychus sp. *, Panama \\
\hline Macraulacini & $\begin{array}{l}\text { Asiocnemis ?mcclayi Muona*, USA, California; A. morawitzi (Semenov) [Mamaev, 1976]; Deltometopus amoenicornis (Say) [[Otto, 2012b]; Dromaeoloides parvulus } \\
\text { (Bonvouloir)*, Australia, NSW, reared; Dromaeoloides spp. *, New Caledonia, Fiji, both reared; D. ?badius (Melsheimer)*, USA, Idaho; D. barnabita (Villa)* [Leiler, 1976]; } \\
\text { ?Dromaeolus lugubris Lea*, Australia, NSW; ?Dromaeolus punctatus (LeConte) }{ }^{*} \text {, USA, Georgia; Fornax distinguendus Bonvouloir [Gardner, 1935]; F. hisamatsui Mamaev } \\
\text { [Mamaev, 1976]; F. gardneri Fleutiaux [Gardner, 1926]; F. holmi Leiler [Leiler, 1990]; F. raja Leiler* [Leiler, 1990]; F. silvestris Fleutiaux [Gardner, 1935]; F. vestitus Fleutiaux } \\
\text { [Gardner, 1935]; Fornax sp. [Costa et al., 2003]; Isarthrus rufipes (Melsheimer) [Mosher, 1919]; Onichodon canadensis (Brown)* [Otto, 2013]; O. orchesides Newman [0tto, } \\
\text { 2013]; O. rugicollis (Fall) [Ott0, 2013]; Pseudoscython parvulus Fleutiaux [Gardner, 1935] }\end{array}$ \\
\hline Nematodini & $\begin{array}{l}\text { Nematodes filum (Fabricius) [Leiler, 1976]; Nematodes penetrans (LeConte) [0tto, 2017]; Nematodes sp. }{ }^{*} \text {, Fiji, Viti Levu, reared; Trigonopleurus rugulosus Bonvouloir*, } \\
\text { Australia, NSW, reared }\end{array}$ \\
\hline CEROPHYTIDAE & Cerophytum elateroides (Latreille) [Costa et al., 2003] \\
\hline THROSCIDAE & Trixagus dermestoides (Linnaeus) [Burakowski, 1975] \\
\hline
\end{tabular}

\section{Eucnemidae: Phyllocerinae}

Gilyarov (1979, figs. 1-3); Klausnitzer (1997, figs. 1-10)

Head capsule undivided (c83), disk-shaped, solid, antennae located in deep pits as in all Eucnemidae except Perothopinae (c85), in contrast to all other discussed taxa. Labrum free as in Pseudomenini, in contrast to all other discussed taxa (c88), wide, short, with long posterior arms attaching it to head capsule, a unique feature. Antennae with four antennomeres as in Pseudomeninae, Elateridae, Cerophytidae and Throscidae, in contrast to other Eucnemidae (c86). Mandibles without retinaculum as in other Eucnemidae except Perothopinae as well as Cerophytidae and Throscidae (c97), free, elongated and inwardly curved as in Pseudomenini, Perothopinae, Anischiinae and most Elateridae, different from those of Throscidae and Cerophytidae as well as other Eucnemidae. Maxillolabial complex completely fused to epicranium as in Eucnemidae except Perothopinae, Pseudomeninae and Anischiinae (c100). Presternum subtriangular, large, strongly sclerotized, darkly pig- mented, forming a single large plate. Legs five-segmented as in Elateridae, Cerophytidae and Throscidae, but contrary to them tiny, all other Eucnemidae with at most one-segmented legs. Abdominal segments without microtrichial patches contrary to other Eucnemidae except Perothopinae, segment IX without urogomphi. Spiracles with closing apparatus as in other Eucnemidae, all Cerophytidae and Throscidae, in contrast to Elateridae.

\section{Eucnemidae: Pseudomeninae, Pseudomenini (Figs. 2A, B, 7B)}

Head capsule undivided (c83), wide, flattened and with anteriorly directed large tooth-like projections on both sides, longitudinally grooved, as in Schizophilini (c82), antennae located in deep pits as in all Eucnemidae except Perothopinae (c85), in contrast to all other discussed taxa (Fig. 2A). Labrum free as in Phyllocerinae, in contrast to all other discussed taxa except Anischiinae (c88), platelike, without posterior arms, a unique feature (Fig. 2B). Antennae with four antennomeres as in Phyllocerinae, 
Schizophilini and Elateridae, Cerophytidae and Throscidae, in contrast to other Eucnemidae (c86). Mandibles without retinaculum as in other Eucnemidae except Perothopinae as well as Cerophytidae and Throscidae (c97), free, elongate and inwardly curved as in Perothopinae, Anischiinae and most Elateridae, different from those of Throscidae and Cerophytidae as well as other Eucnemidae. Maxillolabial complex contiguous with epicranium on each side and incapable of movement, as in Cerophytidae, Throscidae, Perothopinae and Anischiinae, contrary to other Eucnemidae (completely fused) and Elateridae (freely movable) (c100). Presternum subtriangular, pigmented, with paired oblique strong endocarinae, similar to those of Schizophilini and Palaeoxeninae. Legs five-segmented as in Elateridae, Cerophytidae and Throscidae, but contrary to them tiny, all other Eucnemidae with at most one-segmented legs. Abdominal segments with microtrichial patches as in other Eucnemidae except Perothopinae and Phyllocerinae, without areoles, segment 9 with large bifid urogomphi as in Schizophilini. Spiracles with closing apparatus as in other Eucnemidae, all Cerophytidae and Throscidae, in contrast to Elateridae.

\section{Eucnemidae: Pseudomeninae, Schizophilini (Figs. 2C, D, 7C)}

Head capsule undivided (c83), wide, flattened and with anteriorly directed large tooth-like projections on both sides, longitudinally grooved, as in Pseudomenini (c82), antennae located in deep pits as in all Eucnemidae except Perothopinae (c85), in contrast to all other discussed taxa (Fig. 2C). Labrum fused to head as in all other discussed taxa except Pseudomenini, Phyllocerinae and Anischiinae, in contrast to all other discussed taxa (c88), forming an apically excavated nasale-like structure, a unique feature (Fig. 2D). Antennae with four antennomeres as in Phyllocerinae, Schizophilini and Elateridae, Cerophytidae and Throscidae, in contrast to other Eucnemidae (86). Mandibles without retinaculum as in other Eucnemidae except Perothopinae as well as Cerophytidae and Throscidae (c97), free, inward curved but not meeting medially, different from those of all other discussed taxa, laterally with large, sharp tooth-like projections as in most Eucnemidae except Perothopinae, Phyllocerinae, Pseudomenini and Anischiinae. Maxillolabial complex contiguous with epicranium on each side and incapable of movement as in Cerophytidae, Throscidae, Perothopinae, and Anischiinae, contrary to other Eucnemidae (completely fused) and Elateridae (freely movable) (c100). Legs five-segmented as in Elateridae, Cerophytidae and Throscidae, but contrary to them tiny, all other Eucnemidae with at most one-segmented legs. Abdominal segments with microtrichial patches as in other Eucnemidae except Perothopinae and Phyllocerinae, without areoles, segment IX with large bifid urogomphi as in Pseudomenini. Spiracles with closing apparatus as in other Eucnemidae, all Cerophytidae and Throscidae, in contrast to Elateridae.
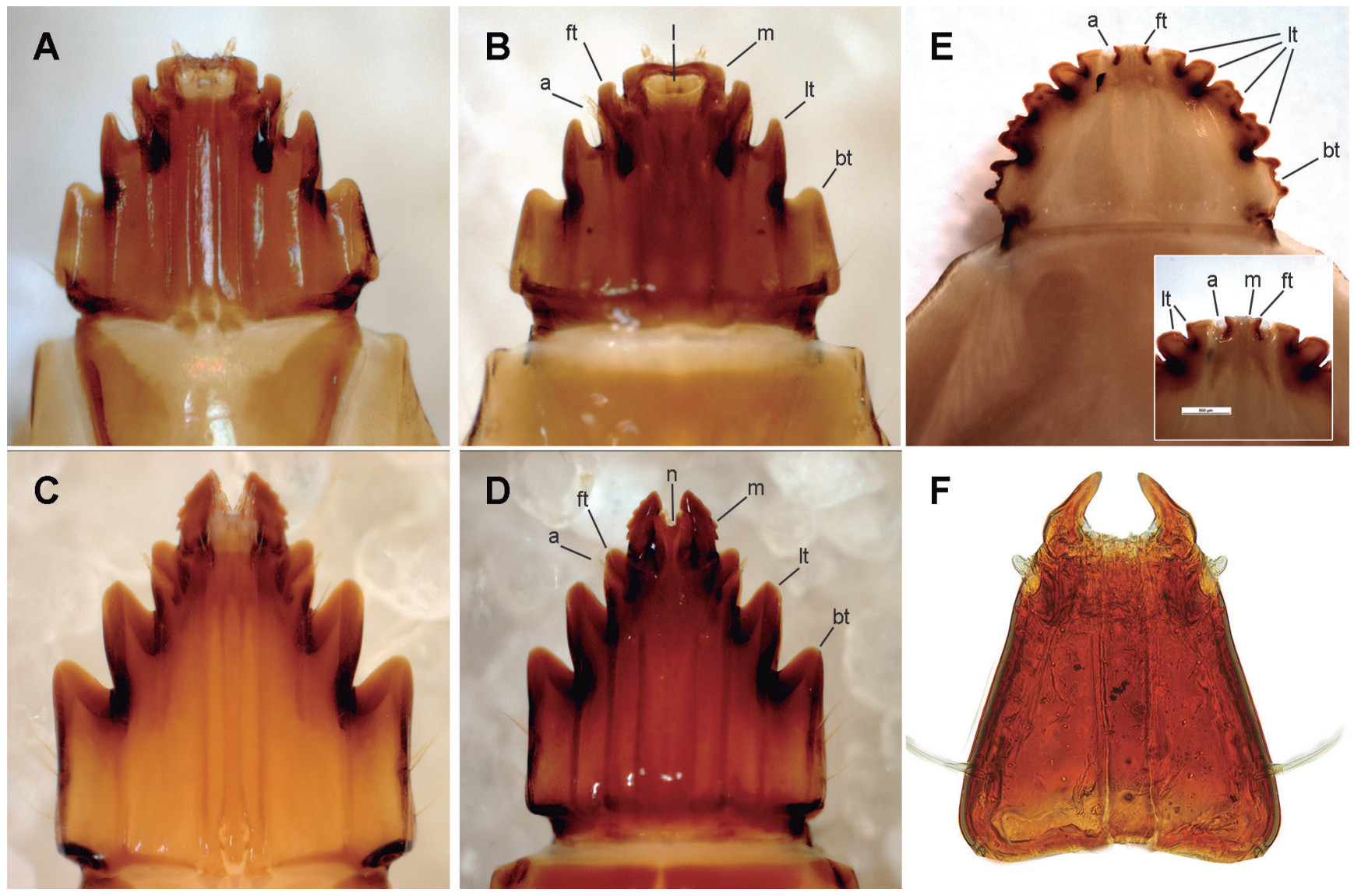

Figure 2. Eucnemidae, larval heads. (A, B) Pseudomenes bakewelli (Bonvouloir), ventral, dorsal; (C, D) Schizophilus subrufus (Randall), ventral, dorsal; (E) Palaeoxenus dohrnii (Horn) dorsal, detail ventral; $(\mathrm{F})$ Anischia kuscheli Lawrence, ventral. $\mathrm{a}=$ antenna, $\mathrm{bt}=$ basal tooth, $\mathrm{ft}=$ front tooth, $\mathrm{I}=$ labrum, $\mathrm{It}=$ lateral tooth, $\mathrm{m}=$ mandible, $\mathrm{n}=$ nasale. 


\section{Eucnemidae: Palaeoxeninae} (Figs. 2E, 7A)

Head capsule wide, flattened, smooth (c84), undivided (c83), forming a semi-circular disk with lateral tooth-like projections, antennae located in deep pits between front tooth and first lateral tooth (Fig. 2E) as in all Eucnemidae except Perothopinae (c85), in contrast to all other discussed taxa. Labrum fused to head without trace of clypeolabral suture as in all Eucnemidae except Phyllocerinae and Pseudomenini (c88). Number of antennomeres reduced as in all Eucnemidae except Phyllocerinae and Pseudomeninae, in contrast to Elateridae, Cerophytidae and Throscidae (86). Mandibles fused to front teeth without trace of sutures, a unique feature (Fig. 2F). Maxillolabial complex completely fused with epicranium as in other Eucnemidae except Perothopinae, Pseudomeninae and Anischiinae, contrary to Cerophytidae and Throscidae (separate, but incapable of movement) and Elateridae (freely movable) (c100). Presternum subtriangular, pigmented, with paired oblique endocarinae, similar to that of Pseudomeninae. Legs present as single setae only as in most Eucnemidae, contrary to Perothopinae, Phyllocerinae, Pseudomeninae, Anischiinae and all non-eucnemids discussed. Abdominal segments with microtrichial patches, without areoles, segment IX with small urogomphi. Spiracles with closing apparatus as in other Eucnemidae, all Cerophytidae and Throscidae, in contrast to Elateridae.

\section{Eucnemidae: Anischiinae}

(Fig. 2F)

Head capsule elongate, flattened, smooth (c84), undivided (c83), antennae located in deep pits as in all Eucnemidae except Perothopinae (c85), in contrast to all other discussed taxa (Fig. 2G). Labrum fused to head without trace of suture as in all Eucnemidae except Phyllocerinae and Pseudomenini (c88). Number of antennomeres reduced as in all Eucnemidae except Phyllocerinae and Pseudomeninae, in contrast to Elateridae, Cerophytidae and Throscidae (c86). Mandibles without retinaculum as in other Eucnemidae except Perothopinae as well as Cerophytidae and Throscidae (c97), free, elongate and inwardly curved as in Schizophilini, Perothopinae and most Elateridae, different from those of Throscidae and Cerophytidae as well as other Eucnemidae. Maxillolabial complex contiguous with epicranium on each side and incapable of movement, as in Cerophytidae, Throscidae, Pseudomeninae and Perothopinae, contrary to other Eucnemidae (completely fused) and Elateridae (freely movable) (c100). Presternum subtriangular, lightly pigmented, weakly delimited, with paired oblique endocarinae. Legs with one segment, a unique feature. Abdominal segments with microtrichial patches, without areoles. Spiracles with closing apparatus as in other Eucnemidae, all Cerophytidae and Throscidae, in contrast to Elateridae.

\section{Eucnemidae: Phlegoninae}

Larva unknown.

\author{
Eucnemidae: Melasinae, excluding Melasini, \\ Hylocharini \\ (Figs. 3A-D)
}

Head capsule wide, flattened (c84), divided into ventral and dorsal plates (c83), forming a semi-circular disk with lateral tooth-like projections, antennae located in deep pits between front tooth and first lateral tooth (Figs. 3A-D) as in all Eucnemidae except Perothopinae (c85), in contrast to all other discussed taxa. Labrum fused to head without trace as in all Eucnemidae except Phyllocerinae and Pseudomenini (c88). Number of antennomeres reduced as in all Eucnemidae except Phyllocerinae and Pseudomeninae, in contrast to Elateridae, Cerophytidae and Throscidae (86). Mandibles very small, either feebly movable or fused to head between mouth and front tooth (Fig. 3). Maxillolabial complex completely fused with epicranium as in other Eucnemidae except Perothopinae, Pseudomeninae and Anischiinae, contrary to Cerophytidae and Throscidae (separate, but incapable of movement) and Elateridae (freely movable) (c100). Presternum mostly undefined, but proventrum usually with two pairs of sclerotizations, one longitudinal medially and one square close to front corners, similar to those of most Melasinae, Eucneminae and Macraulacinae. Legs present as single setae, often visible as dark spot only as in all Eucnemidae except Perothopinae, Phyllocerinae, Pseudomeninae, Anischiinae and all non-eucnemids discussed. Abdominal segments with microtrichial patches and areoles (Muona \& Teräväinen, 2008), segment IX rarely with
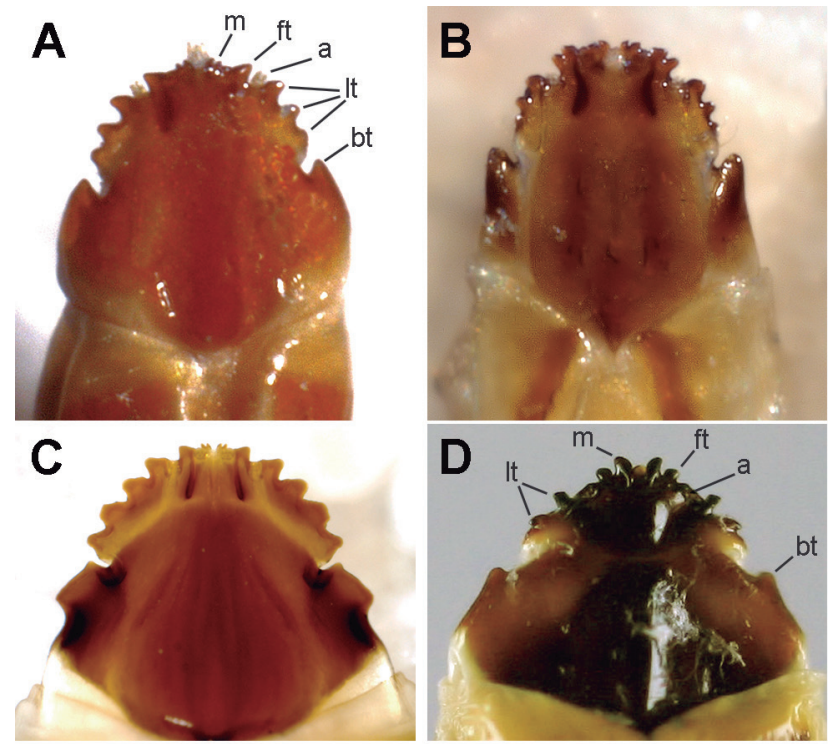

Figure 3. Eucnemidae, Melasinae, larval heads, ventral. (A) Xylophilus corticalis (Paykull); (B) Hylis cariniceps (Reitter); (C) Prodirrhagus; (D) Dirrhagofarsus ernae 0tto, Muona \& MvcClarin. $\mathrm{a}=$ antenna, bt $=$ basal tooth, $\mathrm{ft}=$ front tooth, $\mathrm{It}=$ lateral tooth, $\mathrm{m}=$ mandible. 
minute urogomphi. Spiracles with closing apparatus as in other Eucnemidae, all Cerophytidae and Throscidae, in contrast to Elateridae.

Several Dirhagini exhibit extreme hypermetamorphosis from small triangulin-type larvae (Dirrhagofarsus Fleutiaux) to ones with large exodont mandibles and finally a more "normal" looking larva (Microrhagus Fabricius). Others appear to have a less active, perhaps nearly sessile, development and resemble dipteran larvae (Farsus du Val, Arrhipis Fleutiaux). These unusual developmental types are found also in Nematodini (Nematodes Dejean, Trigonopleurus Bonvouloir) and Eucneminae (Eucnemis Ahrens) and the tendency towards different developemental solutions seems to be a feature uniting the three most specious subfamilies, Eucneminae, Macraulacinae and Melasinae.

\section{Eucnemidae: Melasinae, Melasini} (Fig. 6B)

Head capsule small, cap-like, divided in ventral and dorsal plates but these fused (c83), antennae located in deep pits, basal, lateral and front teeth absent in contrast to all other Eucnemidae except Anischiinae, Nematodini, Hylocharini and all hypermetamorphic Eucneminae. Labrum fused to head without trace as in all Eucnemidae except Phyllocerinae and Pseudomenini (c88). Number of antennomeres reduced as in all Eucnemidae except Phyllocerinae and Pseudomeninae, in contrast to Elateridae, Cerophytidae and Throscidae (c86). Mandibles freely movable, powerful and exodont, large in size as in Hylocharini and Nematodini, contrary to those in other Macraulacinae and Melasinae. Maxillolabial complex completely fused with epicranium as in other Eucnemidae except Perothopinae, Pseudomeninae and Anischiinae, contrary to Cerophytidae and Throscidae (separate, but incapable of movement) and Elateridae (freely movable) (c100). Prothorax substantially wider than mesothorax, ventrally and dorsally with conspicuous T-formed sclerotizations as in Nematodini (3F), mesothorax with sclerotized median rod, presternum unde- fined. Legs visible as dark spots only as in all Eucnemidae except Perothopidae, Phylloceridae, Pseudomeninae, Anischiinae and the non-eucnemids discussed. Abdominal segments without microtrichial patches and areoles contrary to Nematodini (both present) and Hylocharini (areoles present). Spiracles with closing apparatus as in other Eucnemidae, all Cerophytidae and Throscidae, in contrast to Elateridae.

\section{Eucnemidae: Melasinae, Hylocharini} (Fig. 6A)

Head capsule small, cap-like, divided into ventral and dorsal plates but these fused (c83), antennae located in deep pits, hard to see, basal, lateral and front teeth absent in contrast to all other Eucnemidae except Anischiinae, Nematodini, Hylocharini and all hypermetamorphic Eucneminae. Labrum fused to head without trace of suture as in all Eucnemidae except Phyllocerinae and Pseudomenini (c88). Number of antennomeres reduced as in all Eucnemidae except Phyllocerinae and Pseudomeninae, in contrast to Elateridae, Cerophytidae and Throscidae (c86). Mandibles large, freely movable and powerful, exodont as in Melasini and Nematodini, differing from those of all other discussed taxa (6A). Maxillolabial complex completely fused with epicranium as in other Eucnemidae except Perothopinae, Pseudomeninae and Anischiinae, contrary to Cerophytidae and Throscidae (separate, but incapable of movement) and Elateridae (freely movable) (c100). Prothorax substantially wider than mesothorax, ventrally and dorsally with conspicuous plates consisting of rows of wave-like sharp sclerotizations, a unique feature, mesothorax without sclerotizations, presternum undefined. Legs visible as dark spot only as in all Eucnemidae except Perothopidae, Phylloceridae, Pseudomeninae, Anischiinae and the non-eucnemids discussed. Abdominal segments without microtrichial patches contrary to Nematodini, with large areoles contrary to Melasini. Spiracles with closing apparatus as in other Eucnemidae, all Cerophytidae and Throscidae, in contrast to Elateridae.
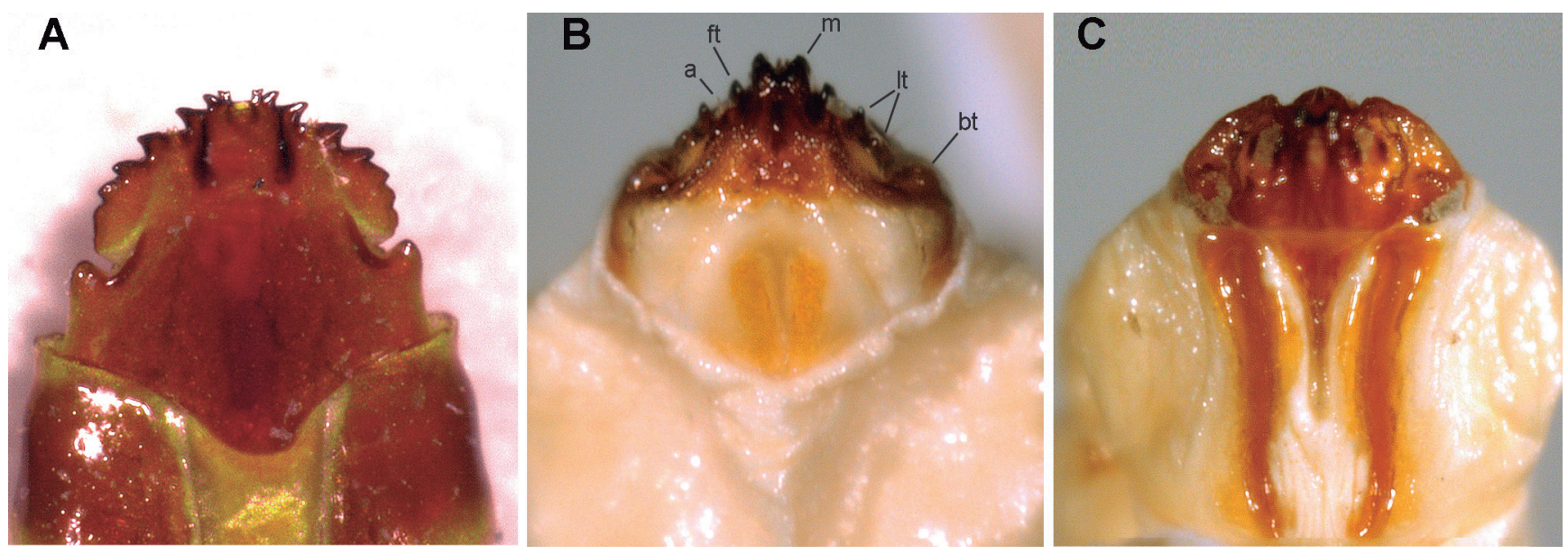

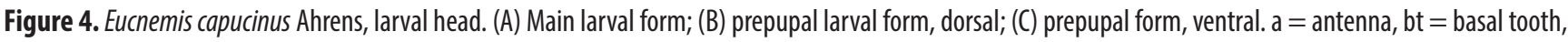
$\mathrm{ft}=$ front tooth, $\mathrm{It}=$ lateral tooth, $\mathrm{m}=$ mandible. 


\section{Eucnemidae: Eucneminae} (Figs. 4C)

The complete developmental sequence of only one genus, Eucnemis Ahrens, is known. During most of the life-history the larva is similar to those of species belonging to Macraulacinae (Fornax, Dromaeolus (s. str.) Kiesenwetter, Dromaeoloides Cobos, Onichodon Newman) and Melasinae (Agalba Broun, Hylis des Gozis, Microrhagus Dejean, Prodirrhagus Fleutiaux, Xylophilus Mannerheim) (Fig. 4A). The main larval form of Eucnemis is, however, conspicuously strongly sclerotized and with large microtrichial patches. The totally different prepupal type has small spike-like structures on head capsule instead of teeth and mandibles and a prominent pair of strong sclerotized rods ventrally on prothorax (Figs. 4B-C). Apparently the developmental strategies are wide in the subfamily, as Stethon LeConte has a similar prepupal form, but the larval stage before that differs radically from the corresponding larval stage of Eucnemis (see Otto \& Gruber, 2016). This variation may reflect the fact that the two genera belong to different tribes, Eucnemini and Mesogenini. The descriptions available for species belonging to a third Eucneminae tribe, Galbitini, suggest that the larvae of Arisus Bonvouloir, Galbimorpha Fleutiaux and Galbites Fleutiaux may offer still further developmental variation, partly similar to that of Farsus du Val in subfamily Melasinae. Unfortunately the descriptions refer only to single stages of these types.

\section{Eucnemidae: Macraulacinae, excluding Nematodini (Figs. 5A-E)}

Head capsule wide, flattened (c84), divided in ventral and dorsal plates (c83), forming a semi-circular disk with lateral tooth-like projections, antennae located in deep pits between front tooth and first lateral tooth (Figs. 2B, 3A, 5A-E) as in all Eucnemidae except Perothopinae (c85), in contrast to all other discussed taxa. Labrum fused to head without trace as in all Eucnemidae except Phyllocerinae and Pseudomenini (c88), Number of antennomeres reduced as in all Eucnemidae except Phyllocerinae and Pseudomeninae, in contrast to Elateridae, Cerophytidae and Throscidae (c86). Mandibles very small, either feebly movable or fused to head between mouth and front teeth. Maxillolabial complex completely fused with epicranium as in other Eucnemidae except Perothopinae, Pseudomeninae and Anischiinae, contrary to Cerophytidae and Throscidae (separate, but incapable of movement) and Elateridae (freely movable). Presternum mostly undefined, but proventer usually with two pairs of sclerotizations, one longitudinal medially and one square close to front corners, similar to those of most Melasinae, Eucneminae and Macraulacinae. Legs present as single setae, often visible as dark spot only as in all Eucnemidae except Perothopinae, Phyllocerinae, Pseudomeninae, Anischiinae and all non-eucnemids discussed. Abdominal segments with microtrichial patch-
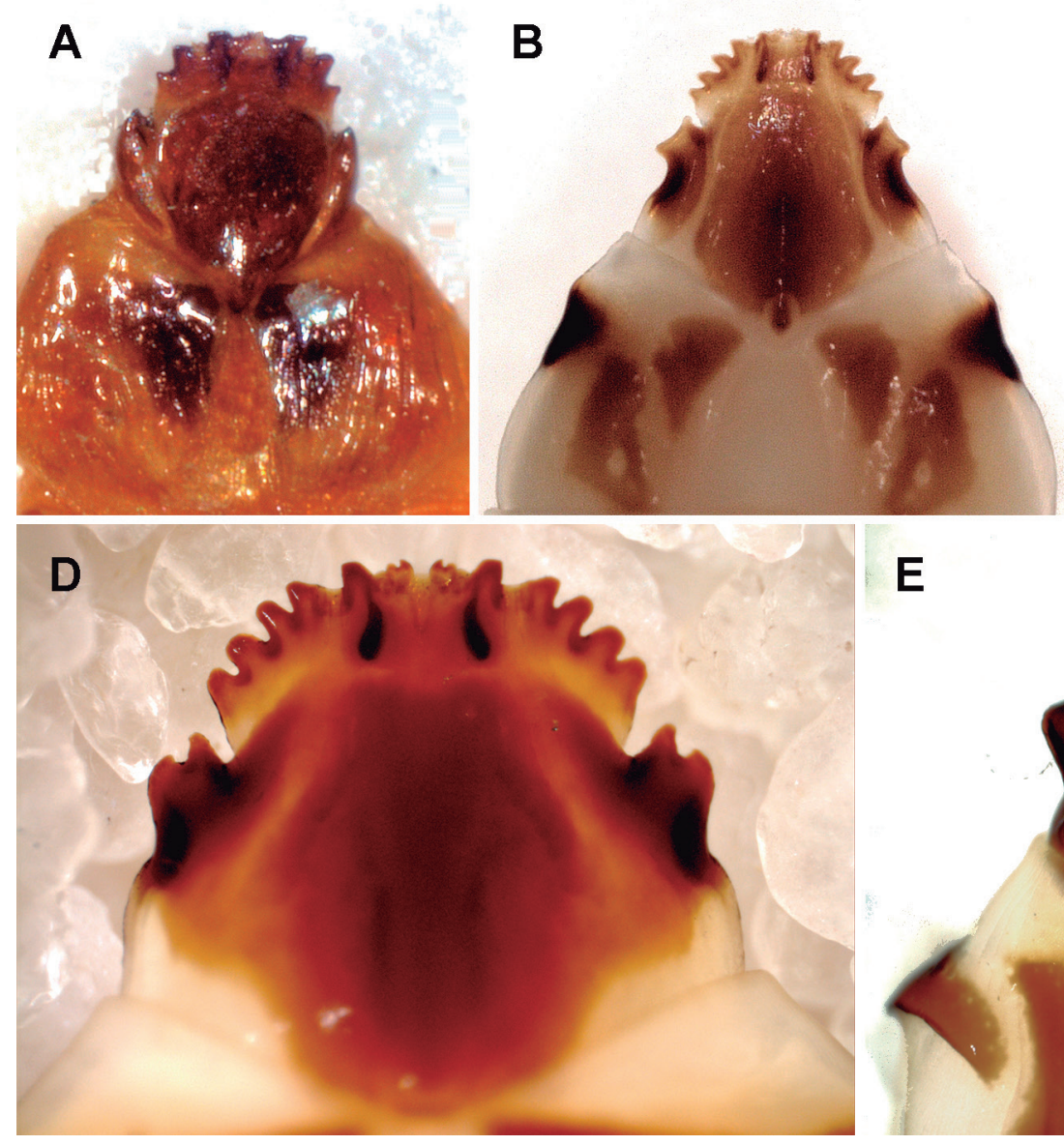
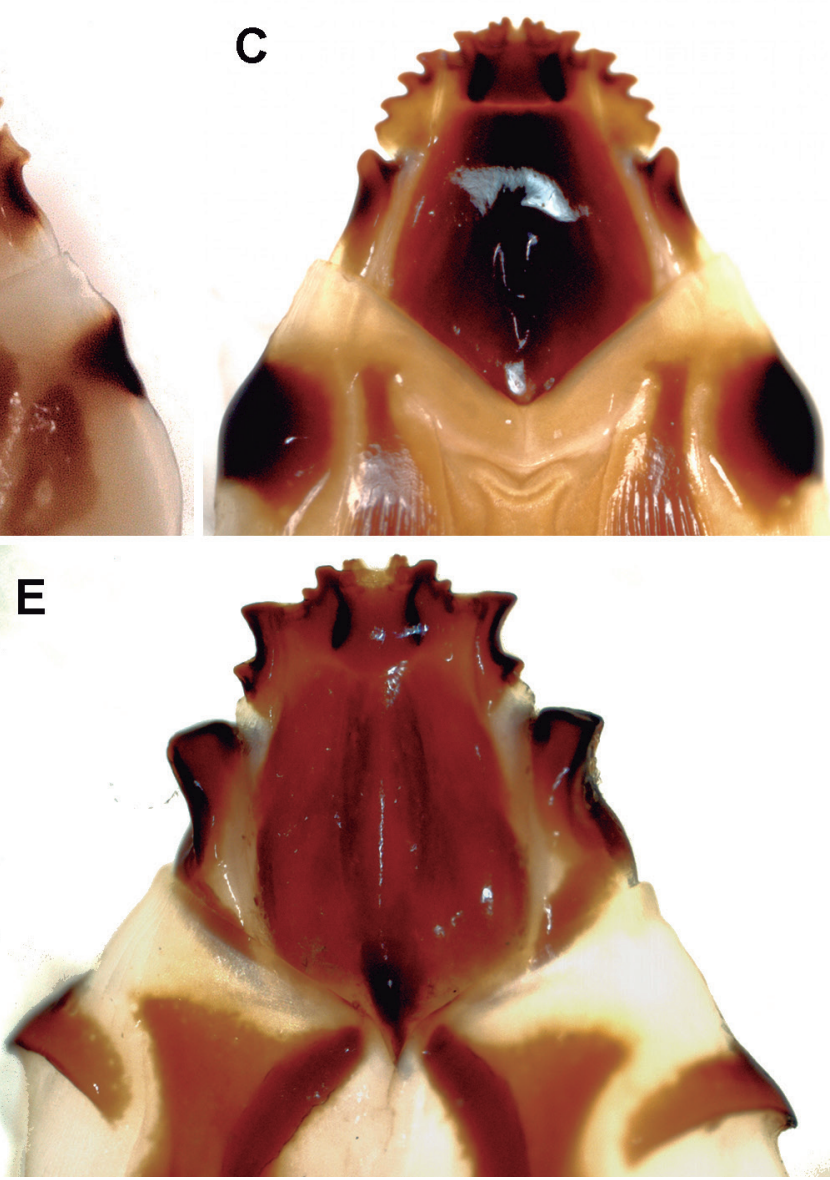

Figure 5. Eucnemidae, Macraulacinae, larval heads, ventral. (A) Dromaeolus barnabita (Villa); (B) Dromaeolus sp.; (C) Dromaeolus ?badius (Melsheimer); (D) Onichodon canadensis (Brown); (E) Asiocnemis mcclayi Muona. 
es and areoles (Muona \& Teräväinen, 2008), segment IX rarely with minute urogomphi. Spiracles with closing apparatus as in other Eucnemidae, all Cerophytidae and Throscidae, in contrast to Elateridae.

\section{Eucnemidae: Macraulacinae, Nematodini (Fig. 6C)}

Head capsule small, cap-like, divided in ventral and dorsal plates but these fused (c83), antennae located in deep pits, basal, lateral and front teeth rudimentary in contrast to all other Eucnemidae except Anischiinae, Melasini, Hylocharini and all extreme hypermetamorphic Eucneminae. Labrum fused to head without trace as in all Eucnemidae except Phyllocerinae and Pseudomenini (c88). Number of antennomeres reduced as in all Eucnemidae except Phyllocerinae and Pseudomeninae, in contrast to Elateridae, Cerophytidae and Throscidae (c86). Mandibles large, freely movable and powerful, exodont as in Hylocharini and Melasini and different from those of all other discussed taxa. Maxillolabial complex completely fused with epicranium as in other Eucnemidae except Perothopinae, Pseudomeninae and Anischiinae, contrary to Cerophytidae and Throscidae (separate, but incapable of movement) and Elateridae (freely movable) (c100). Prothorax substantially wider than mesothorax, ventrally and dorsally with conspicuous T-formed sclerotizations as in Melasini, presternum undefined, mesothorax without sclerotized structures contrary to Melasini. Legs visible as dark spots only as in all Eucnemidae except Perothopinae, Phyllocerinae, Pseudomeninae, Anischiinae and the non-eucnemids discussed. Abdominal segments with both microtrichial patches and areoles contrary to Melasini and Hylocharini. Spiracles with closing apparatus as in other Eucnemidae, all Cerophytidae and Throscidae, in contrast to Elateridae.

\section{Throscidae Burakowski (1975)}

Head capsule smooth (c84), undivided (c83), antennae located on surface as in all Elateridae and
Cerophytidae, in contrast to all Eucnemidae except Perothopinae (c85). Labrum fused to head as in all other discussed taxa except Phyllocerinae and Pseudomenini (c88). Number of antennomeres not reduced as in all Elateridae and Cerophytidae, in contrast to Eucnemidae except Phyllocerinae and Pseudomeninae (c86). Mandibles without retinaculum as in most Eucnemidae and all Cerophytidae and in contrast to Perothops and Elateridae (c97), fused solidly to head, with single lateral blunt tooth, a unique feature. Maxillolabial complex contiguous with epicranium on each side but incapable of movement, as in Cerophytidae, Pseudomeninae and Anischiinae, contrary to most Eucnemidae (completely fused) and Elateridae (freely movable). Presternum undefined, proventer with two pairs of longitudinal and two pairs of transverse sclerotized rods, a unique feature. Legs five-segmented, medium-sized, as in Elateridae and Cerophytidae, much larger than in any Eucnemidae. Abdominal segments without microtrichial patches and areoles as in Elateridae and Cerophytidae, segment IX with very small, simple urogomphi. Spiracles with closing apparatus as in Eucnemidae and Cerophytidae, in contrast to Elateridae.

\section{Cerophytidae \\ Costa et al. (2003)}

Head capsule smooth (c84), undivided (c83), antennae located on surface as in Elateridae and Throscidae, in contrast to all Eucnemidae except Perothopinae (c85). Labrum fused to head as in all other discussed taxa except Phyllocerinae and Pseudomenini (c88). Number of antennomeres not reduced as in all Elateridae, Throscidae, in contrast to Eucnemidae except Phyllocerinae and Pseudomeninae (c86). Mandibles without retinaculum as in most Eucnemidae and all Throscidae, in contrast to Perothops and Elateridae (c97), free, forward directed, non-opposable. Maxillolabial complex contiguous with epicranium on each side, but incapable of movement, as in Throscidae, Pseudomeninae and Anischiinae, contrary to most Eucnemidae (completely fused) and Elateridae (freely movable), short and wide. Presternum undefined, proventer with pair of longitudinal sclerites.
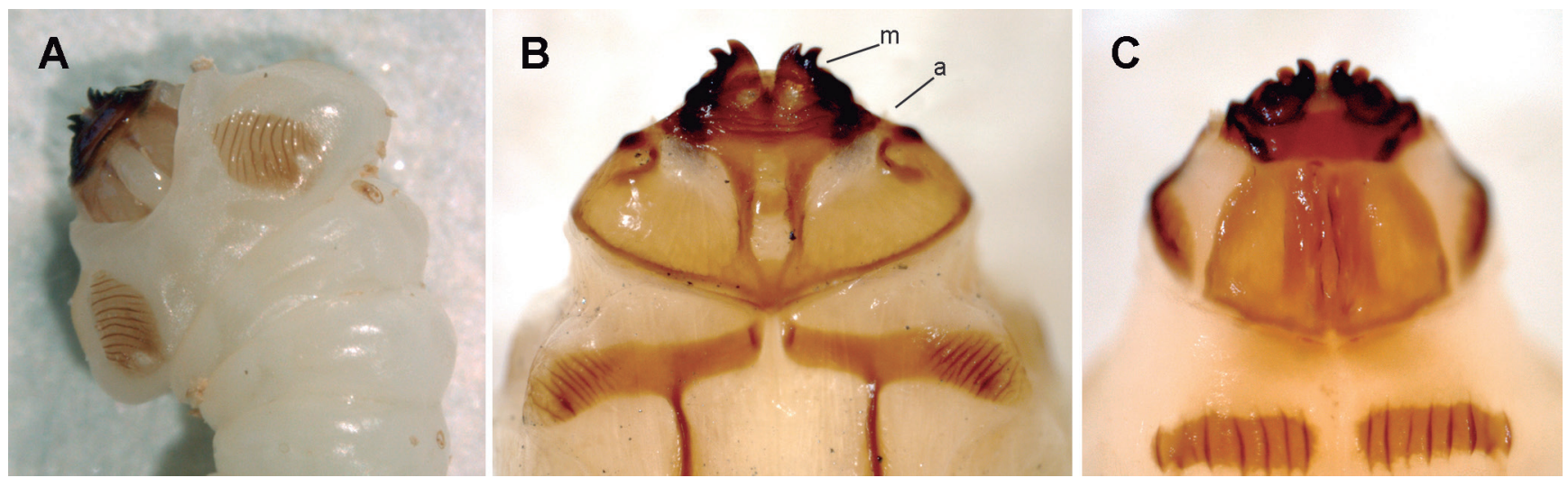

Figure 6. Eucnemidae, larval heads, solid wood boring types. (A) Hylochares cruentatus (Gyllenhal), dorsal; (B) Melasis pectinicornis Melsheimer, dorsal; (C) Trigonopleurus rugulosus Bonvouloir, dorsal. $\mathrm{a}=$ antenna, $\mathrm{m}=$ mandible. 
Legs five-segmented, medium-sized, as in Elateridae and Throscidae, much larger than in any Eucnemidae. Abdominal segments without microtrichial patches and areoles as in Elateridae and Cerophytidae, segment IX with very small, simple urogomphi. Spiracles with closing apparatus as in Eucnemidae and Throscidae, in contrast to Elateridae.

\section{“REAL" Eucnemidae?}

Although not a requirement for our views to hold, we point out that we consider the clicking mechanism a synapomorphy of four elateroid families, Cerophytidae, Throscidae, Eucnemidae and Elateridae. Lawrence et al. (2007) recovered this result with by far the most extensive morphological data set ever analyzed. Based on a large molecular data set, Kundrata et al. (2014) indicated that the clicking mechanism in Elateridae had an independent origin. As we have pointed out earlier, their result was ambiguous. The critical nodes had no resampling support at all and thus the result shown was not reliably based on the data.

The greatly reduced larval legs appear to separate Eucnemidae from all other Elateroidea, including Throscidae, Cerophytidae and Elateridae. This reduction occurs in three stages. Perothops, Phyllocerus Le Peletier \& Serville and Pseudomeninae have five segmented rudimentary legs, Anischia Fleutiaux one segmented legs and the remaining Eucnemidae (Palaeoxeninae, Melasinae, Eucneminae, Macraulacinae) have single setae instead of legs. The reduction of larval legs could thus be a synapomorphy for Eucnemidae sensu Muona (1993). Another larval character, structure of mandibles, is congruent with the larval leg reduction. Species with segmented legs have well-developed inward curving mandibles, the legless ones having exodont mandibles, nearly invariably very small ones as well. The simple larval mandibles are obviously a plesiomorphic feature found in all potential outgroups, but the exodont larval mandibles as well as the total loss of segmented larval legs are synapomorphies of the derived subfamilies: Palaeoxeninae, Melasinae, Eucneminae, Macraulacinae, a group called DE from this on. DE is further characterized by the unique semicircular chisel-shaped head with basal and frontal serrations and one to four further toothshaped ones in between them (Figs. 2E, 3, 4A, 5, 7A). However, the early form of this peculiar head appears to be the type found in Pseudomeninae (Figs. 2A-D). Pseudomenes Fleutiaux has unmodified mandibles and a free labrum (both plesiomorphies) and Schizophilus Bonvouloir mandibles with serrations on lateral surfaces and a fused labrum (both apomorphies shared with $D E)$. These differences are significant in an evolutionary sense, uniting Schizophilus with the DE and separating Pseudomenes as the sister-group of them all. In such a scheme, using phyletic sequencing, Schizophilinae would become the sister-group of the (unnamed) DE clade and Pseudomeninae the sister-group of the combined (unnamed) clade with Schizophilinae and DE.
The clade (Melasinae (Eucneminae, Macraulacinae)) within DE shares further previously ignored synapomorphies: head divided in dorsal and ventral plates and an undefined prothoracic presternum. Its sister-group Palaeoxenus Horn has a plesiomorphic entire head capsule and a well-developed presternum.

\section{Perothopinae, Phyllocerinae, Anischinae?}

The larvae of the remaining three basal Eucnemidae subfamilies (Perothopinae, Phyllocerinae, Anischinae) are very different from each other.

Anischia has microtrichial patches and antennae placed in deep cavities, both features of eucnemids. Its position between Palaeoxenus and (Melasinae (Eucneminae, Macraulacinae)) (Lawrence et al., 2007) appears problematic, as Anischia possesses several plesiomorphic features hard to see as apomorphic reversals needed for such a placement: unmodified head capsule, elongate, normal mandibles and legs with one real segment. We find this result untenable. To place Anischia basally as the sister group of (Pseudomeninae (Schizophilinae (DE))) is a reasonable possibility. It would mean that the larval labrum was fused to head a least twice in the Eucnemidae lineage, once in Anischia and again in Schizophilus. On the other hand, Perothops with many plesiomorphic features, e.g., antennae attached to surface of head, has a fused larval labrum as well. Thus it is clear that this character state cannot be optimized without multiple changes anyway, irrespective of the cladogram. The free larval labrum in Phyllocerinae and Pseudomenes point to the basal position of eucnemids in the elateroid phylogeny, as the only other taxon to show this plesiomorphic feature is Brachypsectra.

The maxillolabial complex is contiguous with epicranium on each side and incapable of movement in Perothops, Anischia, Pseudomenes and Schizophilus as well as in Cerophytidae and Throscidae, whereas it is solidly fused to epicranium in Phyllocerus as well as in the DE. These fusions are not similar, however. In Phyllocerus, all ventral structures form one single hard plate without details. In Palaeoxenus the separate structures of ventral head as well as prothorax are still discernable (Fig. 7A), whereas in Melasinae, Eucneminae and Macraulacinae the fusion is nearly complete and only mentum and/or submentum can be seen (Figs. 7D-F).

Elateridae as well as all potential out-groups have a free maxillolabial complex, the contiguous state being present in cerophytids, throscids and Perothops, Anischia, Pseudomenes and Schizophilus. This could be a synapomorphy connecting the three clades together. Phyllocerus larva is strongly sclerotized and highly specialized for living in the black earth soil. The apparent similarity in larval maxillolabial complex to lignicolous derived eucnemids is not due to identical structures, but superficial similarity. Phyllocerus larva has deep antennal cavities, however. This might be seen as further support for closer relationship with eucnemids, excluding Perothops. 
The fused maxillolabial complex appears to be another previously ignored synapomorphy for the (Pseudomenini (Schizophilini (DE))) clade. The sclerotized dark plates and rods found in most Melasinae, Eucneminae and Macraulacinae larvae may be homologs of larval features still visible in Pseudomenes, Schizophilus and Palaeoxenus. The longitudinal rods/fields could be the remnants of the powerful presternal oblique carinae and the paired sclerotization on front corners of proventer homologs of the sclerotized ventral suture edges (Figs. 7D-F).

\section{Do the larval characters support existing hypothesis for Eucnemidae relationships?}

Do our undoubtedly speculative ideas (based on actual character states, however) fit the adult structures and the hypothesis based on those? Traditionally eucnemids were separated from elaterids by the completely connate abdominal ventrites and concealed labrum. Neither of these characters suffices today. Anischia fails on both counts with three connate ventrites and a visible labrum. Phyllocerus has only four connate ventrites as do Cerophytidae and Elateridae, whereas Perothops, Pseudomeninae, and all derived Eucnemidae have five connate ventrites, but so does Throscidae. A further character, the attachment of pedicel to scape is subapical in all Eucnemidae, but the same holds for Cerophytidae and a few Elateridae (Thylacosterninae, Lissominae). Numerous other characters prove this state in elaterids to be homoplastic, but the cerophytids might well be the sister-group to some or all eucnemids based on the antennal structure.

The female reproductive tract seems to provide illuminating evidence. First, potential out-groups Dascillidae and Artematopidae as well as Throscidae, Cerophytidae and Elateridae all have special sclerites or asperities in bursa copulatrix, Eucnemidae and Brachyspectridae do not (c73). Secondly, Elateridae have colleterial glands, while Eucnemidae, Cerophytidae and Throscidae do not (c70). Third, Perothops, Phyllocerinae, Pseudomeninae, Palaeoxenus and Phlegon Laporte as well as basal Melasinae (e.g., Hylochares Latreille), Eucneminae (e.g., Phaenocerus Bonvouloir, Pinaroo Muona) and Macraulacinae (e.g., Langurioscython Heller, Dictyeucnemis Lea, Ceratogonys Perty) have a bifurcate

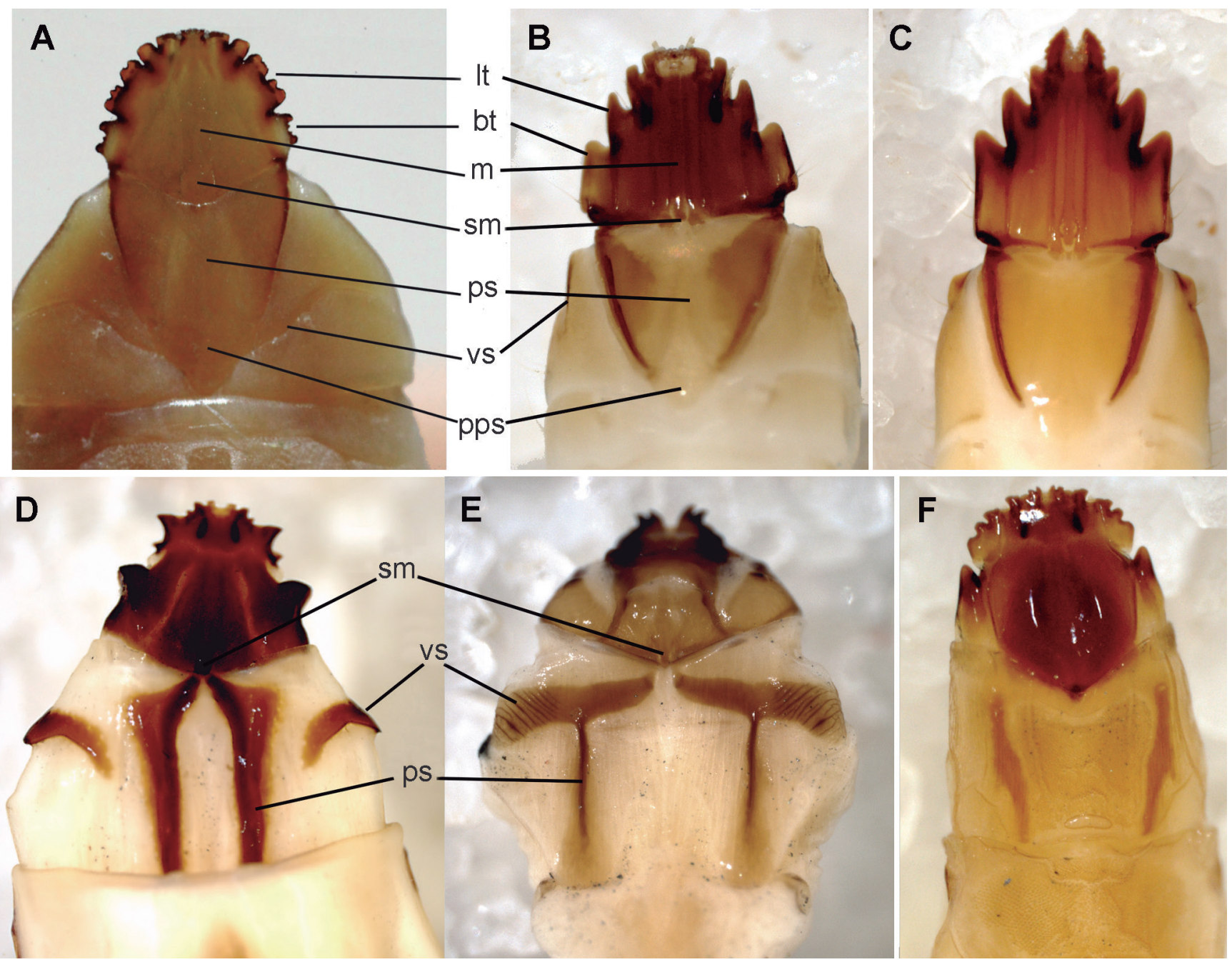

Figure 7. Eucnemidae, larval heads, ventral. (A) Palaeoxenus dohrnii (Horn); (B) Pseudomenes bakewelli (Bonvouloir); (C) Schizophilus subrufus (Randall); (D) Asiocnemis meclayi Muona; (E) Melasis pectinicornis Melsheimer; (F) Rhagomicrus bonvouloiri (Say). bt = basal tooth, It $=$ lateral tooth, $\mathrm{m}=\mathrm{mentum}$, $\mathrm{pps}=$ posterior presternal sclerite, $\mathrm{ps}=$ presternum, $\mathrm{sm}=$ submentum, vs $=$ ventral suture. 
bursa, a synapomorphy not known in other Elateroidea (c72; Muona, 1993).

The unarmed bursa is clearly a synapomorphy for Eucnemidae s.l. as it is not present in any putative outgroup (c72). The bifurcate bursa is a synapomorphy for eucnemids as well, but it has reversed in all derive members of Macraulacinae, Eucneminae and Melasinae, quite clearly independently in all three clades.

The colleterial glands appear to be the only elaterid synapomorphy found this far, all other related taxa lacking these. It is a strong character not known to have reversed.

Otto \& Gruber (2016) drew attention to the peculiar grooves and large punctures in the elytral apices of the eucnemid Stethon. These specialized pores, not previously noticed, had not caught the attention they deserved. A search has shown that these structures (excretory organs?) are found in all Eucnemidae except Perothops, Phyllocerus and a few highly derived Macraulacinae. This splendid discovery appears to be a synapomorphy for all true lignicolous eucnemids.

The hypermetamorphic taxa, i.e., many if not all Eucneminae, many Dirhagini and all Nematodini, are not identical either in structure or in development. There appears to be a pattern present in many Melasinae, Eucneminae and Macraulacinae of early triungulin type larvae followed by chisel-shaped head type stage and finally variable reduction of hard structures in the last stage. Either of the two final stages may dominate the full development.

The extreme larval forms, type Galbitini, resembling Diptera larvae may spend their whole life in one chamber. The extraoral digestion in wood infested with fungus makes this approach feasible.

One of the authors (JM) has followed the development of an undescribed Nematodes Berthold species in Viti Levu, Fiji. The first instar larva had powerful exodont mandibles, similar to the macraulacine Fornax gardneri Fleutiaux first instar larva (Gardner, 1926). These larvae were found in seemingly hard wood of an unidentified rattan. They developed into a typical chisel-shaped head type in a few weeks and during the same period the substrate had become soft and penetrable. After several such stages the larvae assumed the Nematodes appearance described by Leiler (1976) and Otto (2017). Finally, the further reduced prepupal form emerged. The key here, as with Melasini and Hylochares, seems to be the consistency of the substrate. All these species start their development in hard wood infested by fungus. Early on the larvae need to be able to penetrate the substrate with strong mandibles, but later in their development, if the wood becomes soft enough, a standard derived eucnemid larval type is the solution.

Lignicolous larvae are constantly in danger of being parasitized or eaten by predators. The hydraulic method of penetrating the wood used by eucnemid larvae leaves no real galleries and the absence of working mandibles reduce the noise produced substantially. It is definitely the most advanced approach for moving around within wood in secrecy. The extraoral feeding leaves open the further possibility of not moving at all, if fungal growth is constantly available for extraoral feeding. This may well be the reason behind the extreme larval forms, which appear to spend the whole life in one chamber. It is easy to understand, that such a solution would also benefit from highly mobile early stages capable of finding the right one location, a triungulin type larva.

The few derived eucnemids with larvae penetrating hard wood need strong mandibles and a large prothorax with strong muscles and gripping surface structures to provide the mouthparts leverage. Other beetle larvae with the same kind of approach to wood-boring have developed similar looking solutions, e.g., Buprestidae and Cerambycidae. Details differ substantially; however, those taxa have a free labrum and normally biting mandibles instead of fused labrum and exodont mandibles.

In our view the external similarity of Hylocharini, Melasini and Nematodini is due to repeated invasions into hard wood. In Melasini and Hylocharini the whole development takes place in hard wood. In Nematodini, the larvae use different phases of rot during their development. This may well be the strategy for Eucnemis as well. We have observed minute larvae in moist, very soft inner wall of hollow trees, with larger larvae in more solid and drier wood, deeper in the substrate.

We acknowledge the fact that evolutionary hypotheses must be based on global analytical results. Evolutionary novelties, synapomorphies, exist only in connection with an analysis of a specific data set. On the other hand, we believe it is useful to examine the characters supporting the groups previously analytically established. We have here looked at larval features not used in the evolutionary hypothesis previously produced. The larval features discussed appeared to help to clarify the relationships within Eucnemidae and Elateroidea to some extent. They were especially useful in pointing out serious problems as well as strong evolutionary signals within Eucnemidae.

\section{CONCLUSIONS}

First, the true lignicolous eucnemids include Pseudomeninae, Schizophilinae, Palaeoxeninae, Eucneminae, Melasinae and Macraulacinae. Phlegoninae with unknown larvae fits amongst the eucnemid taxa because of the unmodified, bifurcate bursa. This is in agreement with the earlier analytical hypothesis but refines the situation with respect to Pseudomeninae sensu Muona (1993). All sister-group relationships found new support from larval features and larval features helped to discover further adult synapomorphies. In the scheme here accepted the tribe Schizophilini Muona, 1993 is shown to be the sister-group of the subfamilies Palaeoxeninae, Phlegoninae, Melasinae, Eucneminae and Macraulacinae. To reflect this in a scheme of phyletic sequencing it is regarded a subfamily, Schizophilinae Muona, 1993 new status.

Second, further evidence for the placement of Phyllocerinae and Anischiinae are needed. They may 
well be true eucnemids, but the sister-group relationships need further study. Phyllocerus larva has many special features related to its subterranean mode of life in a special, compact environment, but the unmodified, bifurcate bursa indicates it belongs to the eucnemid lineage. Anischia appears to be a complex of real eucnemid synapomorphies united with reductive features.

Third, Perothops appears to be among basal taxa of the eucnemid lineage, but it may share sister-group relationships with non-eucnemid taxa as well. If this turns out to be the case, the families have to be redefined.

\section{ACKNOWLEDGMENTS}

Parts of this study have been funded by the Finnish Academy of Sciences (grant 79243 to JM) and the Helsinki University (TAKSON and EVERCLADES projects, JM).

\section{REFERENCES}

Brüstle, L. \& Muona, J. 2009. Life-history studies versus genetic markers - the case of Hylochares cruentatus (Gyllenhal, 1808) (Col., Eucnemidae). Journal of Zoological Systematics and Evolutionary Research, 42: 100-107. D01

Böving, A.G. \& Craighead, F.C. 1931. An illustrated synopsis of the principal larval forms of the order Coleoptera. Entomologica Americana, 11: 1-351.

Burakowski, B. 1975. Development, distribution and habits of Trixagus dermestoides (L.), with notes on the Throscidae and Lissomidae (Coleoptera, Elateroidea). Annales Zoologici, Warszawa, 32: 375-405.

Burakowski, B. 1989. Hypermetamorphosis of Rhocopus attenuatus (Mäklin) (Coleoptera, Eucnemidae). Annales Zoologici, Warszawa, 42: 165-180.

Chang, H.; Muona, J.; Pu, H.; Xu, L.; Wang, C.; Teräväinen, M.; Ren, D.; Yang, Q.; Zhang, X.\& Jia, S. 2016. Chinese Cretaceous larva exposes a southern Californian living fossil (Insecta, Coleoptera, Eucnemidae). Cladistics, 32(2): 211-214. DOI

Costa, C.; Casari-Chen, S.A. \& Vanin, S.A. 1985. Larvae of Neotropical Coleoptera. XII. Artematopoidea, Artematopidae. Revista Brasileira de Entomologia, 29: 309-314.

Costa, C.; Vanin, S.A.; Lawrence, J.F. \& Ide, S. 2003. Systemtics and cladistics analysis of Cerophytidae (Elateroidea: Coleoptera). Systematic Entomology, 28: 375-407.

Crowson, R.A. 1955. The natural classification of the families of Coleoptera. London, Nathaniel Lloyd \& C0. 187p.

Emden, F.l. van. 1932. Die Larven der Callirhipini, eine mutmassliche Cerophytum-Larve und Familien-Bestimmungtabelle der Larven der Malacodermata-Sternoxia Reihe (Coleoptera). Bulletin et Annales de la Société Entomologique de Belgique, 72: 199-259, pls. 11-13.

Ford, E.J. \& Spilman, T.J. 1979. Biology and immature stages of Dirhagofarsus lewisi, a species new to the United States (Coleoptera, Eucnemidae). The Coleopterists Bulletin, 33: 75-83.

Gardner, J.C.M. 1926. (a) Description of the early stages of Fornax gardneri Fleut. (Melasidae, Col.). (b) Description of the larva of Atractocerus emarginatus Cast. (Lymexylonidae, Col.). Indian Forest Records, 12: 273-286.

Gardner, J.C.M. 1935. Immature stages of Indian Coleoptera (17) (Eucnemidae). Indian Forest Records (New Series) Entomology, 1: 79-93, plates I-II.

Gilyarov, M.S. 1979. A larva of Phyllocerus and its position in the system of Elateroidea. (in Russian). Zoologicheskii Zhurnal, 58: 655-663.
Klausnitzer, B. 1997. Zur Kenntnis der Larve von Phyllocerus Lepeletier \& Serville (Coleoptera, Eucnemidae, Phyllocerinae). Berichte des Naturwissenschaftlich-medizinischer Verein Innsbruck, 84: 371-378.

Kundrata, R. \& Bocak, L. 2011. The phylogeny and limits of Elateridae (Insecta, Coleoptera): is there a common tendency of click beetles to soft-bodiedness and neoteny? Zoologica Scripta, 40: 364-378. D01

Kundrata, R.; Bocakova, M. \& Bocak, L. 2014. The comprehensive phylogeny of the superfamily Elateroidea (Coleoptera: Elateriformia). Molecular Phylogenetics and Evolution, 76: 162-171. DOI

Kusy, D.; Motyka, M.; Bocek, M.; Vogler, A. \& Bocak, L. 2018. Genome sequences identify three families of Coleoptera as morphologically derived click beetles (Elateridae). Scientific Reports, 8(1): 17084. D0I

Lawrence, J.F.; Muona, J.; Teräväinen, M.; Ståhls, G. \& Vahtera, V. 2007. Anischia, Perothops and the phylogeny of Elateroidea (Coleoptera: Elateriformia). Insect Systematics \& Evolution, 38: 205-239. DOI

Lawrence, J.F.; Ślipiński, A.; Seago, A.E.; Thayer, M.K.; Newton, A.F. \& Marvaldi, A.E. 2011. Phylogeny of the Coleoptera Based on Morphological Characters of Adults and Larvae. Annales Zoologici, 61: 1-217. D0I

Leiler, T.E. 1976. Zur Kenntnis der Entwicklungsstadien und der Lebensweise nord- und mitteleuropäischer Eucnemiden (Col.). Entomologische Blätter für Biologie und Systematik der Käfer, 72: 10-50.

Leiler, T.E. 1990. Beschreibung einiger malaysischer Eucnemiden-Arten, ihrer Larven un Lebensweise (Col.). Entomologische Blätter für Biologie und Systematik der Käfer, 86: 145-158.

Lucht, W. 1981. Die Präimaginalstadien von Hypocoelus olexai Palm (Col., Eucnemidae) nebst Bestimmungstabelle der Larven Nord- und Mitteleuropäischer Hypocoelus -Arten. Entomologische Blätter für Biologi und Systematik der Käfer, 77: 61-74.

Lundberg, 1962. Något om svenska eucnemider. Entomologisk Tidsskrift, 83: 89-94.

Mamaev, B.M. 1976. Morphological types of xylophagous beetle larvae (Coleoptera, Eucnemidae) and their evolutionary importance. In: Mamaev, B.M. (Ed.). Evolutionary Morphology of Wood-Boring Larvae. Moscow, Nauka. p. 136-155.

Mosher, E. 1919. Notes on the immature stages of Deltometopus rufipes Mels. (Coleoptera, Eucnemidae). Annals of the Entomological Society of America, 12: 49-53, plate IV.

Muona, J. 1993. Review of the phylogeny, classification and biology of the family Eucnemidae (Coleoptera). Entomologica Scandinavica. Supplement, 44: 1-133.

Muona, J. \& Teräväinen, M. 2008. Notes on the biology and morphology of false click-beetle larvae (Coleoptera: Eucnemidae). The Coleopterists Bulletin, 62: 475-479.

Nelson, G. 1974. Classification as an expression of phylogenetic relationships. Systematic Zoology, 22: 344-359.

Nemeth, T. \& Otto, R. 2016. Notes on the bionomics of Farsus dubius (Piller \& Mitterpacher, 1783) (Coleoptera: Eucnemidae: Melasinae), with observations on its hypermetamorphic development. Elateridarium, 10: 133-144.

0tto, R. 2012a. Eucnemid larvae of the Nearctic Region. Part I: Description of the larva of Rhagomicrus bonvouloiri (Horn, 1886) (Coleoptera: Eucnemidae: Melasinae: Dirrhagini), with notes on its biology. The Coleopterists Bulletin, 66(3): 219-223.

0tto, R. 2012b. Eucnemid Larvae of the Nearctic Region. Part Il: Description of the Mature Larva of Deltometopus amoenicornis (Say, 1836) (Coleoptera: Eucnemidae: Macraulacinae: Macraulacini), with notes on its biology. The Coleopterists Bulletin, 66(3): 285-288.

0tto, R. 2013. Eucnemid Larvae of the Nearctic Region. Part III: Mature Larval Descriptions for Three Species of Onichodon Newman, 1838 (Coleoptera: 
Eucnemidae: Macraulacini, with notes on their biology. The Coleopterists Bulletin, 67: 97-106.

Otto, R. 2014. Eucnemid Larvae of the Nearctic Region. Part IV: Description of the Mature Larva of Entomophthalmus rufiolus (LeConte, 1866) (Coleoptera: Eucnemidae: Dirhagini), with Notes on its biology The Coleopterists Bulletin, 68: 331-335.

Otto, R. 2015. Eucnemid larvae of the Nearctic region. Part V: Fifth instar larval descriptions for eight species of Microrhagus Dejean, 1833 (Coleoptera: Eucnemidae: Melasinae: Dirhagini), with descriptions of four new species and notes on their biology. Insecta Mundi, 421: 1-43.

Otto, R. 2017. Eucnemid larvae of the Nearctic Region. Part VII: Description of the larvae of Nematodes penetrans (LeConte, 1852) (Coleoptera: Eucnemidae: Macraulacinae: Nematodini), with notes on its hypermetamorphic life cycle. Insecta Mundi, 545: 1-9.

Otto, R. \& Gruber, J. 2016. Eucnemid larvae of the Nearctic region. Part Vl: Descriptions of the fifth instar and prepupal larval stages Stethon pectorosus LeConte, 1866 (Coleoptera: Eucnemidae: Eucneminae: Mesogenini), with notes on their biology. Insecta Mundi, 474: 1-11.

Otto, R.; Muona, J. \& McClarin, J. 2014. Description of Dirrhagofarsus ernae n. sp. with a key to the known Dirrhagofarsus species (Coleoptera: Eucnemidae). Zootaxa, 3878: 179-184.

Otto, R. \& Young, D. 1998. Description of the Larva of Schizophilus subrufus (Randall) (Coleoptera: Eucnemidae: Pseudomeninae), with Notes on Its Natural History. The Coleopterists Bulletin, 52: 306-312.

Palm, T. 1955 Weitere Beiträge zur Kenntnis der schwedischen HypocoelusArten (Col. Eucnemidae). Opuscula Entomologica, 20: 211-217.

Peterson, A. 1960. Larvae of Insects. Coleoptera, Diptera, Neuroptera, Siphonaptera, Mecoptera, Trichoptera. Columbus, A. Paterson. part II, $416 \mathrm{p}$.

Van Horn, R.W. 1909. Notes on some of the Eucnemidae of the eastern states. (Coleoptera, Eucnemidae). Proceedings of the entomological Society Washington, 11: 54-62. 